\title{
Bird monitoring programs in Ontario: What have we got and what do we need?
}

\author{
Charles M. Francis ${ }^{1,2}$, Peter J. Blancher ${ }^{1}$ and R. Dean Phoenix ${ }^{3}$
}

\begin{abstract}
Bird population monitoring should be designed to enhance conservation of birds through informing policy decisions and management actions. Many different bird surveys are undertaken in Ontario ranging from province-wide multi-species programs such as the Ontario Breeding Bird Atlas to single-species localized surveys for Species at Risk. Although most surveys provide some useful contributions towards understanding the status of bird populations, there remain significant gaps in both species and geographic coverages, especially in the northern half of the province, and few surveys are sufficient for evaluating the specific effects of current management practices on birds. Enhancing bird monitoring in the province should first involve clearly defining, quantitatively, the information required for management, conservation and decision-making, in the context of an adaptive management cycle, and then identifying the most cost-effective monitoring programs to obtain that information. This can most effectively be implemented through a cooperative effort involving all parties with an interest in bird monitoring data including federal and provincial government agencies, environmental non-government organizations, and industry.
\end{abstract}

Key words: bird population monitoring, evaluation, adaptive management, decision-making

\section{RÉSUMÉ}

Les relevés des populations d’oiseaux devraient être conçus pour accroitre la préservation des oiseaux au moyen de décisions règlementées d'information et de mesures d’aménagement. Nombreux et différents sont les relevés doiseaux effectués en Ontario allant des programmes couvrant toute la province et plusieurs espèces comme l'Atlas des oiseaux nicheurs de l'Ontario, aux relevés localisés restreints à une seule espèce dans le cas des espèces en péril. Même si la plupart des relevés constitue une contribution significative permettant une compréhension de létat des populations d’oiseaux, il existe malgré tout des lacunes importantes tant au niveau des espèces que de leur répartition géographique, particulièrement dans le nord de la province et rares sont les relevés permettant une évaluation des effets spécifiques des pratiques courantes d'aménagement sur les oiseaux. Afin d’améliorer les relevés ornithologiques provinciaux, il faudrait en premier lieu clairement et quantitativement définir l'information requise à des fins d’aménagement, de préservation et de prise de décisions dans le contexte d'un cycle d’aménagement adaptatif et, par la suite, identifier les programmes de surveillance les plus rentables permettant d’obtenir cette information. Le tout peut être implanté le plus efficacement possible moyennant la coopération de toutes les parties intéressées par les données des relevés ornithologiques qu'il sagisse d’agences du gouvernement fédéral ou provincial, d’organisations environnementales non gouvernementales et de l'industrie.

Mots clés : relevé des populations d’oiseaux, évaluation, aménagement adaptatif, prise de décision

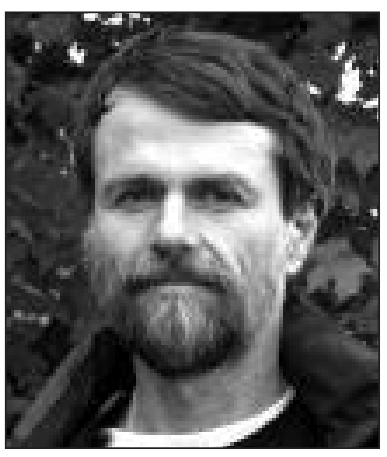

Charles M. Francis

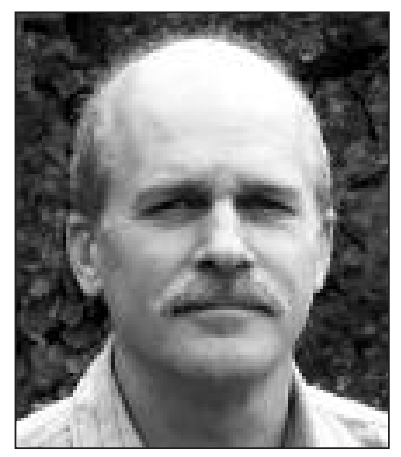

Peter J. Blancher

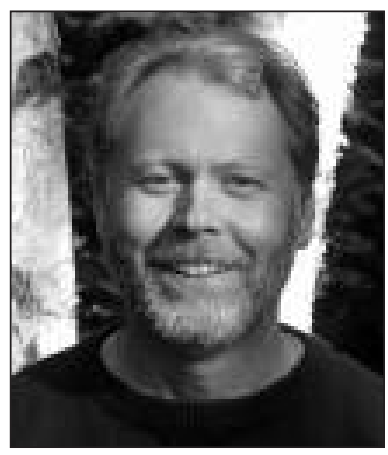

R. Dean Phoenix

\footnotetext{
${ }^{1}$ Environment Canada, National Wildlife Research Centre, 1125 Colonel By Drive, Ottawa, ON K1A 0H3.

${ }^{2}$ Corresponding author. E-mail: charles.francis@ec.gc.ca

${ }^{3}$ Ontario Ministry of Natural Resources, 5520 Hwy 101 East, South Porcupine, ON P0N 1H0.
} 


\section{Introduction}

Monitoring of bird populations can provide information that can be used to help maintain bird populations and communities through identifying the conservation status of each species (current population status and recent trends), helping to identify possible causes of population change, and evaluating the impacts of management activities designed to maintain or enhance bird populations (Baillie 1990, U.S. NABCI Committee 2007). However, monitoring programs require significant resources, both in terms of time (whether volunteers or professionals) and money (e.g., for travel, data management, data analysis).

When making decisions about investment in monitoring programs, it is important to ensure that the data provided will be relevant and sufficient for making management decisions (U.S. NABCI Committee 2007), and that the programs will be cost-effective. Field et al. (2007) asserted that, throughout the world, many millions of dollars are wasted on monitoring programs that have little chance of achieving their ultimate objectives of enhancing management or conservation. They suggested that problems arise due to monitoring programs that are too short-term to detect changes of ecological relevance, that are not sufficiently well designed statistically to make valid inferences, or that do not provide information that is relevant for decision-making. Surveys may also be of limited value if the data collected are not appropriately analyzed or reported to make the information available to decision-makers (U.S. NABCI Committee 2007). Nichols and Williams (2007) suggested that monitoring programs not explicitly tied to decision-making in a scientific framework are an inefficient use of resources, although they acknowledge that even an inefficient program may still provide some useful information.

In Ontario, many bird monitoring programs have been developed by various groups including federal and provincial agencies, non-government organizations and industry. Given the amount of money being invested both in monitoring programs and bird conservation activities in Ontario, it is important to ensure that there is a good match between the need for information and the information being provided, and that the monitoring is designed to be as effective as possible.

Here, we consider the ways that bird monitoring information should feed into bird conservation and management, define criteria to be used in evaluating bird monitoring programs, illustrate how these criteria can be used to evaluate the strengths and weaknesses of some of the existing bird population monitoring programs in Ontario, and then provide some recommendations on ways to enhance future bird population monitoring in the province, considering who needs to have the information and how it might most effectively be gathered to maximize benefits to conservation decision-making. ment actions.

\section{The Need for Monitoring Information in Bird Con- servation}

Prior to evaluating any bird monitoring program, it is necessary to identify the potential ways that the information from the program can and should be used. As noted above, failure to identify appropriate objectives of monitoring programs has the potential to lead to major inefficiencies (Field et al. 2007, Nichols and Williams 2007).

Bird population monitoring can contribute to management of bird populations in several ways (U.S. NABCI Committee 2007), including helping to define population objectives (Rich et al. 2004), helping to identify appropriate candidate management options, and evaluating the effectiveness of management actions. Ideally, these should all be an integrated part of an adaptive management cycle (Fig. 1) in such a way that the same programs can inform several components of the process.

Population monitoring programs contribute to setting population objectives by providing information required to

Fig. 1. Information gathered through bird population monitoring programs contributes to an adaptive management cycle in several ways including assessing the status of species, defining conservation objectives, developing conservation plans, and evaluating manage-

assess the status of each species (Sauer et al. 2003, Lambert et al. 2009). Preferably, monitoring programs should provide information on the current population size of each species and recent population trends. These data can then be combined with best available knowledge of the species' demography and actual or potential threats (including use of expert opinion if quantitative data are not available) to assess the current status of each species, together with projected changes in the status based on current threats. This may involve not only assessment of whether a species may become at risk of extinction, using criteria such as those of the IUCN (2001), but also consideration of whether a smaller change in abundance may lead to changes in ecosystem functions or values.

As noted in Fig. 1, assessing a species status is only part of the process of defining population objectives-it is also necessary to consider societal values (Nichols and Williams 2007). Declining populations of a particular species do not 
necessarily mean that the objective should be to increase the population. If a species has declined in recent years, but still remains common and widespread, it may be acceptable to manage to maintain current population levels, or even to allow some level of continued decline. These decisions are value judgements and need to consider other factors such as the potential causes of declines, costs of management to halt declines, the impact of any management on other species and values and the ecological or economic value of the species (e.g., for bird-watching or tourism). Nevertheless, these decisions cannot be made effectively without information from monitoring programs.

Bird population monitoring programs can also contribute to conservation and management planning through informing the choice of appropriate management actions. As a minimum, monitoring provides information on whether population objectives have already been met, and hence whether further specific management actions are required. If populations are below the objective levels, and management is required to enhance populations, well designed monitoring programs may help to identify factors that are limiting the populations and suggest possible actions to reverse those factors (Baillie 1990). For example, programs may provide information on habitat requirements of species if survey locations are appropriately georeferenced and analyzed in conjunction with habitat information from the same locations (Thogmartin et al. 2004). Spatial variation in bird population trends could be compared with spatial data on habitat change, to determine whether population change is correlated with habitat changes on the breeding grounds, or whether it may be caused by other factors (such as mortality on migration or changes in wintering habitat). Comparisons of population trends for different groups of species could potentially provide information by identifying common patterns. If sufficient monitoring data on vital rates (e.g., survival or nesting success) are available, it may be possible to determine whether population changes are being driven by changes in survival rates or changes in productivity which, in turn, may suggest appropriate management actions (although the most appropriate factors to target for management may not necessarily be the same factors that led to a decline; Nichols and Williams 2007).

Monitoring can also contribute to improved management through evaluating the effectiveness of management actions. Regardless of how much information is available on potential causes of population change, there will always be some uncertainty about the effectiveness of any given management action. Monitoring will be most effective if it is designed to evaluate predictions of an explicit, quantitative model about the impact of the management (Nichols and Williams 2007). These models need not be complex but should be explicitly stated and designed in such a way that testable quantitative predictions are available.

As illustrated in Fig. 1, this whole process can be considered part of a management cycle, with dynamic changes to management actions and/or objectives. Feedback on management actions, through effective monitoring programs, will increase understanding of the system and lead to better management in the future. Effective management actions will enhance the status of species that are below their population objectives while maintaining populations of species that are within their target population range. However, evaluation of the response to management may also suggest a need to change strategy. For example, it may become apparent that management is targeted at the wrong stage of the life cycle. Forest management to enhance habitat for a particular species will be ineffective if the species is limited in its wintering grounds. In this case, it may be more effective to focus conservation efforts through international activities. In some cases, it may be necessary to adjust the population objectives, if it is determined that the original goals are unrealistic and cannot be attained.

\section{Criteria for Evaluating Bird Population Monitoring Programs}

The first step in evaluating a bird population monitoring program, from the perspective of bird conservation and management, is to determine how the monitoring contributes to conservation. Does the program provide information that fits, in an appropriate manner, in the adaptive management cycle described above? Several questions that can be asked of a program to evaluate this include:

- Will the monitoring data help with decision-making and, if so, how?

- Are there significant risks associated with not undertaking the monitoring?

- Will these risks be reduced in a cost-effective manner by the monitoring?

- Will the monitoring program increase understanding of system processes and appropriate management actions?

- Will the monitoring help evaluate management actions? The results of such an analysis can sometimes be surprising. For example, Field et al. (2004) developed a model that suggested, for an economically valuable population of koalas (Phascolarctos cinereus) in Australia, a monitoring program to evaluate their status was not worthwhile, because it was more cost-effective to carry out management actions for the species regardless of the results of the monitoring program. This was due mainly to the unusually high cost of failing to manage the species relative to the costs of management. However, in most situations, a well-designed monitoring program is likely to result in substantial benefits for decision-making, through directing management to the highest priority species, avoiding unnecessary management activities, or by ensuring that management is actually effective.

Assuming that this first step identifies a program as potentially being useful (i.e., the answers to most or all of the above questions are "yes"), the second step is to consider whether the survey design is sufficient to meet its objectives:

- Is the sampling design appropriate to allow valid extrapolation to the area/population of interest?

- Is the geographic scope/scale of the program suitable for the scale of decision-making being considered?

- Are the survey protocols suitable for the species being surveyed?

- Is the sample size sufficient to achieve the required level of precision/statistical power?

For many bird monitoring programs, it is not possible to achieve an ideal study design due to constraints such as difficulties in accessing random locations, variation among observers, or challenges in correcting for incomplete detectability. In these cases, the critical question is whether 
the potential bias due to these limitations is small relative to the changes in parameters being estimated.

Finally, if the survey is determined to be relevant and sufficiently well-designed, it is important to ensure that the results are analyzed and made available in a timely manner.

- Are the data properly computerized, documented and well managed in a secure environment?

- Are the data appropriately analyzed in a timely manner using statistically sound approaches to answer the required questions?

- Are the analyses provided in a manner that supports effective decision-making?

Statistical analysis of bird monitoring programs can be challenging because they rarely fit within standard statistical paradigms. Various analysis techniques based on different underlying assumptions may result in different conclusions, even for such well-known data sets as the Breeding Bird Survey (Thomas and Martin 1996). Recent developments such as Bayesian hierarchical models provide a framework that is increasingly being adopted for these types of data (Link and Sauer 2002, Link et al. 2006), but further work is still needed to compare the results with those from older analysis methods.

Programs developed specifically for monitoring should ideally be designed with quantitative goals and consideration of exactly how the data will be used for conservation and management. Only in this way will it be possible to ensure that they are providing all necessary information, that the information will be well used, and that the survey will be costeffective. Clear definition of objectives is particularly important for ensuring that management actions are evaluated as part of the adaptive management cycle (Fig. 1).

However, some bird surveys that were not actually designed as monitoring programs now provide valuable monitoring information. For example, the Christmas Bird Count was originally developed in 1900 by Frank Chapman as a recreational activity for bird-watchers as an alternative to the more destructive Christmas "Side Hunt". It has since grown into the longest available large-scale quantitative time series on bird populations in North America. Although recreational birding remains one of its key features, a recent review of the program suggests that with appropriate analysis methods the data can provide valuable information on the status of bird populations, although some changes to count protocols could improve the quality of the results (Dunn et al. 2005). Similarly, checklist programs such as eBird ${ }^{5}$ were developed to capture information from birders who are out watching birds for other reasons. These also can provide useful information on population trends (Dunn et al. 1996), and checklist type approaches have been adopted as the primary survey method for some monitoring programs, such as the Australian Breeding Bird Atlas (Barrett et al. 2003). These types of existing surveys should be considered in any evaluation of monitoring requirements, because they may provide data that is sufficient to support many types of decision-making, reducing the need for expensive, custom-designed monitoring programs.

\footnotetext{
${ }^{4}$ http://www.audubon.org/bird/cbc/history.html

${ }^{5} \mathrm{http}: / /$ ebird.org/content/canada/
}

\section{Evaluating Existing Bird Population Monitoring Pro- grams in Ontario}

A large number of different bird surveys are currently being undertaken in Ontario, of which a partial list is provided in Table 1. These range from province-wide surveys such as the Ontario Breeding Bird Atlas to localized surveys for Species at Risk, such as Hooded Warblers (Wilsonia citrina) or Loggerhead Shrikes (Lanius ludovicianus).

Here, we review some of the strengths and weaknesses for 7 surveys that formed the primary basis for a recent assessment of the status of forest birds in Ontario (Blancher et al. 2009). These surveys were selected as being the largest-scale and longest-running, multi-species surveys that provide information on breeding status of forest birds (including species associated with forested wetlands) in Ontario. The proposed units for planning bird conservation in North America are Bird Conservation Regions (BCRs; U.S. NABCI 2000), so we consider these surveys from the perspective of the 4 BCRs in Ontario, although only the Breeding Bird Atlas provides fairly good coverage in all regions (Fig. 2).

Here we evaluate these surveys primarily from the perspective of how well they contribute to evaluating the status of birds in Ontario, although their potential contribution to understanding causes of population change and evaluating management actions is also discussed where appropriate.

\section{Breeding Bird Survey}

The North American Breeding Bird Survey is a continentwide survey, consisting of 503 -minute point counts at $0.8-\mathrm{km}$ intervals on randomly selected routes along secondary and tertiary roads (Robbins et al. 1986). Each route is surveyed once per year by a skilled observer on a single morning each breeding season.

Strengths: This is the statistically most robust and best developed survey for most species of landbirds in North America (U.S. Geological Survey 2007). It is particularly useful for estimating population trajectories and assessing conservation status of a broad range of species (Rich et al. 2004). Data from this survey can be analyzed at various scales from national and continental down to regional (Sauer et al. 2003). Data are well managed and secure and are publicly available through the Internet along with the results of annually updated analyses. Analysis methods are well developed but, as with all bird surveys discussed here, different approaches are recommended by different statisticians (Thomas and Martin 1996), and new methods are continually being developed (Link and Sauer 2002). Data can also be analyzed in a spatially explicit manner to provide information on habitat associations and their potential impacts on population change (e.g., Thogmartin et al. 2004). Due to its continental importance, the survey has been subject to periodic external review (O'Connor et al. 2000, U.S. Geological Survey 2007). These reviews have strongly affirmed the value of the survey, but have also recommended enhancements which are gradually being implemented to further improve its usefulness.

Limitations: The major limitation of the Breeding Bird Survey in Ontario is its restricted geographic coverage (Fig. 2, 3). Relatively few routes have been run in BCR 8 , many of which have only been run occasionally, and none is run in BCR 7 (Fig. 3). In addition, the survey design and sampling intensity is most appropriate for estimating population status 
Table 1. A sample of some of the more extensive bird surveys undertaken in Ontario within recent years, indicating the approximate years and species covered. Surveys marked with * ${ }^{*}$ are discussed more extensively in the text.

\begin{tabular}{|c|c|c|}
\hline Survey Name & Survey Duration & Species sampled \\
\hline \multicolumn{3}{|l|}{ Breeding Season Surveys } \\
\hline Ontario Breeding Bird Atlas ${ }^{* *}$ & $1981-1985$ and $2001-2005$ & All \\
\hline Breeding Bird Survey ${ }^{\star *}$ & 1968 onwards & All \\
\hline Ontario Nocturnal Owl Survey ${ }^{* *}$ & 1995 onwards & Nocturnal owls \\
\hline Forest Bird Monitoring Program ** & 1987 onwards & Forest landbirds \\
\hline Black Duck helicopter surveys ${ }^{* *}$ & 1990 onwards & $\begin{array}{l}\text { Waterfowl and a few other } \\
\text { wetland species }\end{array}$ \\
\hline \multicolumn{3}{|l|}{ Southern Ontario Breeding Waterfowl } \\
\hline Pair and Habitat Survey ${ }^{\star *}$ & 1971 onwards & All breeding waterfowl \\
\hline Hudson Bay Lowlands Canada Goose Survey & 1989 onwards & Canada Geese \\
\hline Red-shouldered Hawk Survey & 1990-2006 & $\begin{array}{l}\text { Red-shoulder Hawks, other } \\
\text { raptors and woodpeckers }\end{array}$ \\
\hline Marsh Monitoring Program & 1994 onwards & Marsh associated birds \\
\hline Woodcock Singing Ground Survey & 1968 onwards & American Woodcock \\
\hline Great Lakes Colonial Waterbird Surveys & 1976 onwards & Terns, gulls, herons, cormorants \\
\hline \multicolumn{3}{|l|}{ Migration Surveys } \\
\hline Canadian Migration Monitoring Network ${ }^{* *}$ & 1961 onwards & All landbirds \\
\hline Hawk Watches & 1974 onwards & Raptors \\
\hline Ontario shorebirds surveys & 1976 onwards & Shorebirds \\
\hline \multicolumn{3}{|l|}{ Winter Surveys } \\
\hline Winter Waterfowl Surveys & 1968 onwards & Wintering waterfowl \\
\hline Christmas Bird Count & 1900 onwards & All species \\
\hline Project FeederWatch & 1976 onwards & All species that visit feeders \\
\hline \multicolumn{3}{|l|}{ Year-round Surveys } \\
\hline Checklist programs (eBird) & $\begin{array}{l}2002 \text { onwards } \\
\text { (but many older data also included) }\end{array}$ & All species \\
\hline \multicolumn{3}{|l|}{ Demographic Monitoring } \\
\hline Canadian Lakes Loon Survey & 1981 onwards & Common Loon \\
\hline Ontario Nest Records Scheme & 1956 onwards & All species \\
\hline Monitoring Avian Productivity and Survival (MAPS) & 1989 onwards (later in Ontario) & Forest songbirds \\
\hline
\end{tabular}

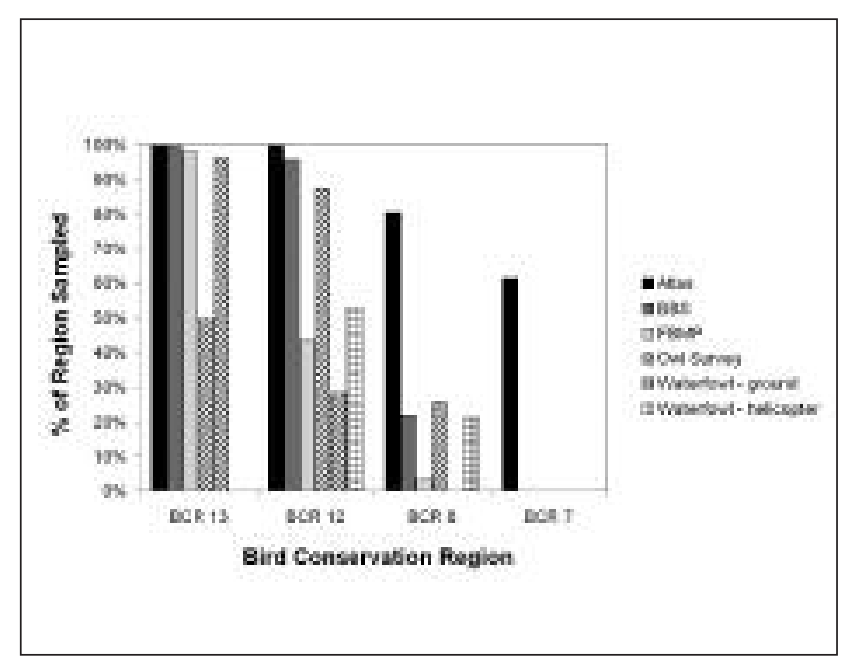

Fig. 2. Geographic coverage of selected major bird surveys in Ontario by Bird Conservation Region (BCR). Percent of region covered was based on land area in degree blocks of latitude / longitude that included one or more survey units meeting minimum target coverage in the past 10 years. at relatively large geographic scales (e.g., across a BCR). It is less suitable for smaller-scale analyses, such as evaluation of the impacts of specific habitat management actions, due to the limited sampling intensity at small scales and the roadside limitation, although recent changes to survey data management, including georeferencing each stop location and entering data for individual stops have enhanced its value for some of these types of analyses (Thogmartin et al. 2004). Some species are not well covered, such as nocturnal birds, many waterbirds, and most rare species.

Concerns have also been expressed about variation in detectability and observers (U.S. Geological Survey 2007), but these are a challenge for all songbird surveys currently being conducted in Ontario and can be addressed as well, or better, by the Breeding Bird Survey, through appropriate design and analysis (e.g., adjusting for observers in analysis) than any other similar survey.

\section{Ontario Breeding Bird Atlas}

Each Ontario Breeding Bird Atlas was an intensive effort over a 5-year period to map the distribution of birds throughout the province. Two atlases have been carried out, the first from 


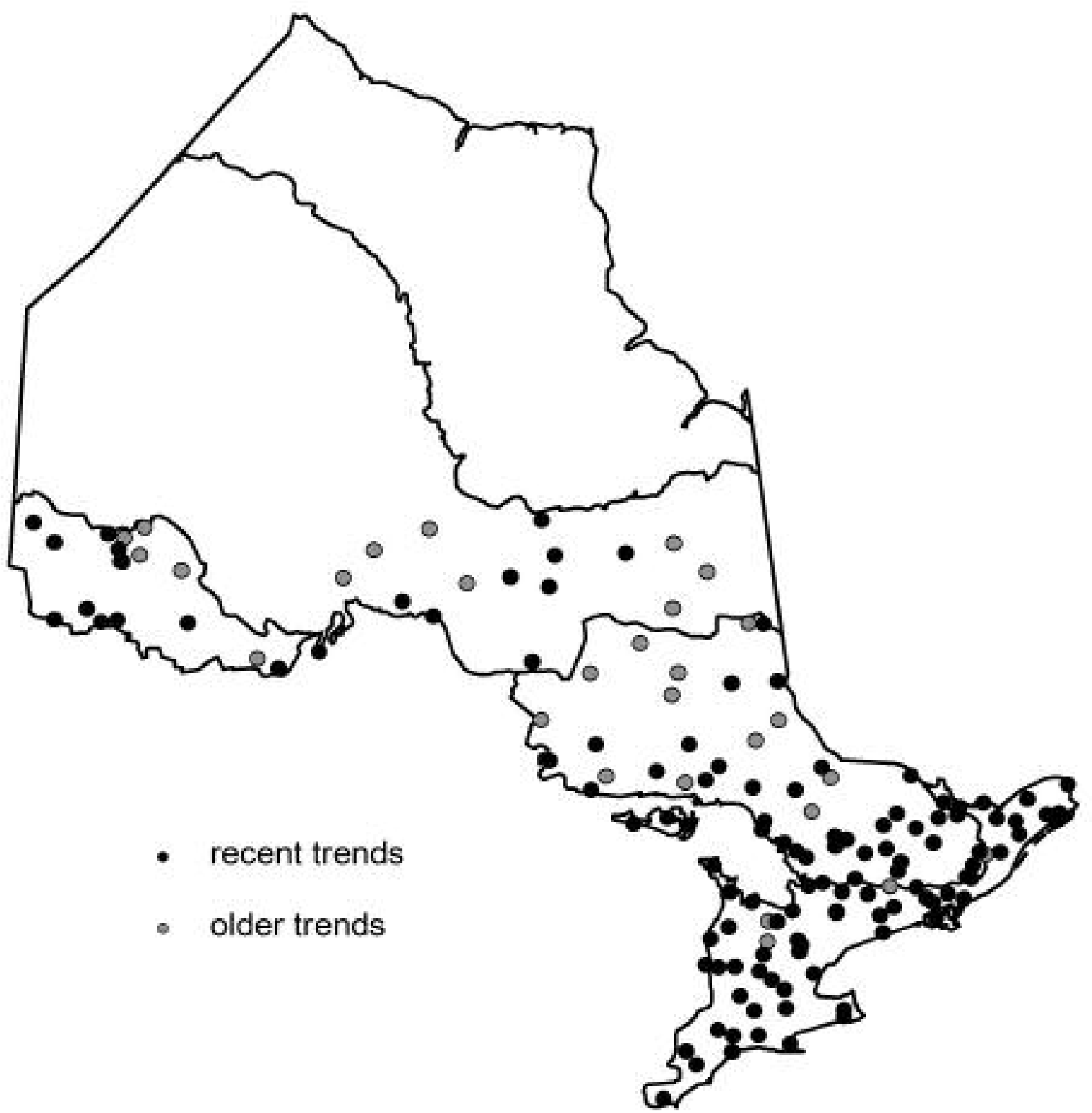

Fig. 3. Distribution of Breeding Bird Survey routes within each of the bird conservation regions in Ontario (BCRs $7,8,12,13$ from north to south respectively) distinguishing routes with sufficient data to estimate recent trends (within the past 10 years) from those with enough data to estimate trends over some period in the past 40 years, but not recently.

1981 to 1985 (Cadman et al. 1987) and the second from 2001 to 2005 (Cadman et al. 2007). Breeding evidence data have been recorded for every species at the $10 \times 10 \mathrm{~km}$ square level, with more precise locations for rare and colonial species. For the second atlas, about 69 000, 5-minute point counts were undertaken at randomly selected roadside locations and a smaller number of off-road sites.

Strengths: Both atlases mobilized tremendous resources, including thousands of volunteer and many professional birders, to obtain the most extensive geographic coverage of any survey in the province (Fig. 2), but coverage remains much more intense in the south (Fig. 4). Atlases provide relatively detailed information on the geographic distribution of each species. Changes in counts between the 2 atlases were the primary information source for trends in bird populations over the past 20 years for most species in the northern BCRs 7 and 8 (Blancher et al. 2009). Atlas data also provided extensive information on many species too rare to detect reliably on other generalized surveys. The second atlas was used as a framework for a series of surveys specifically designed to evaluate the impacts of forest management on bird communities, while simultaneously gathering information on distri- 


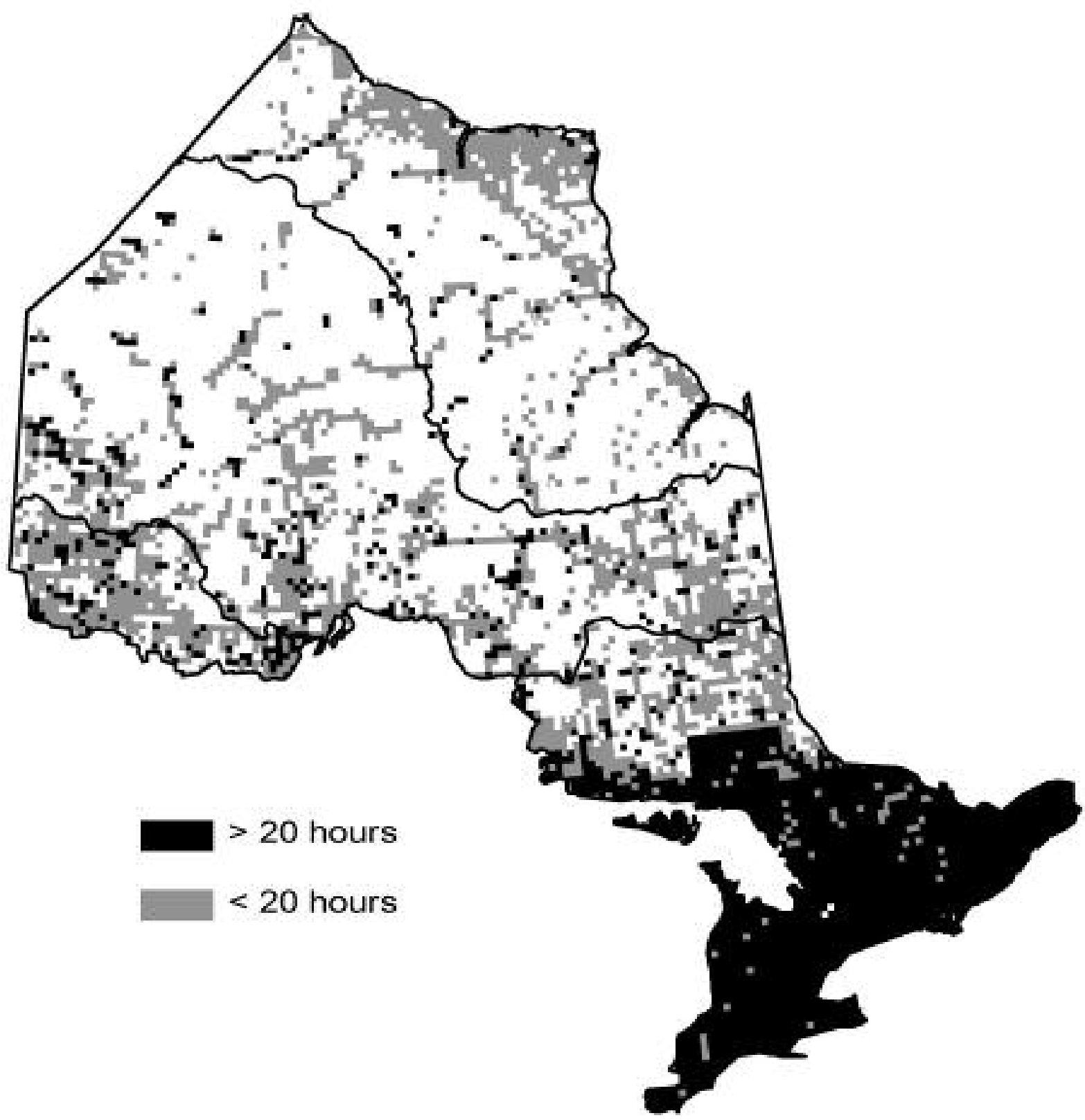

Fig. 4. Geographic distribution of survey effort as a measure of coverage of the second Ontario Breeding Bird Atlas (2001-2005), by $10 \times 10 \mathrm{~km}$ square. Although coverage in the north was much less intense than in the south, in aggregate there were still more than 60 hours of coverage in nearly all $100 \times 100 \mathrm{~km}$ blocks.

bution and status for the atlas (Cadman et al. 2007, R. Zimmerling ${ }^{6}$ and C.M. Francis, unpublished data). Atlases also have many other benefits, including education and training; for example, training of volunteers for atlas point counts has provided a pool of expertise that can now benefit other survey programs.

Limitations: Trend analysis from the first to the second atlas was based on changes in the probability of detecting a

${ }^{6}$ Wildlife Biologist, Golder Associates Ltd., 62 Steacie Drive, Kanata, ON K2K 2A9. species in a $10 \times 10 \mathrm{~km}$ square after adjusting for effort (Blancher et al. 2007), but this underestimates the change in population numbers, especially for common species (Fig. 5). In BCR 13, population change estimated from the Breeding Bird Survey was nearly 8 times greater than the estimated change in distribution for common species (Fig. 5b), but only 1.5 times greater for uncommon species (Fig. 5d). Differences in effort between the 2 atlases may also have led to some biases in estimating change (Blancher et al. 2007) because non-point count effort was not standardized, and there can be important differences in efficiency of effort that cannot be 

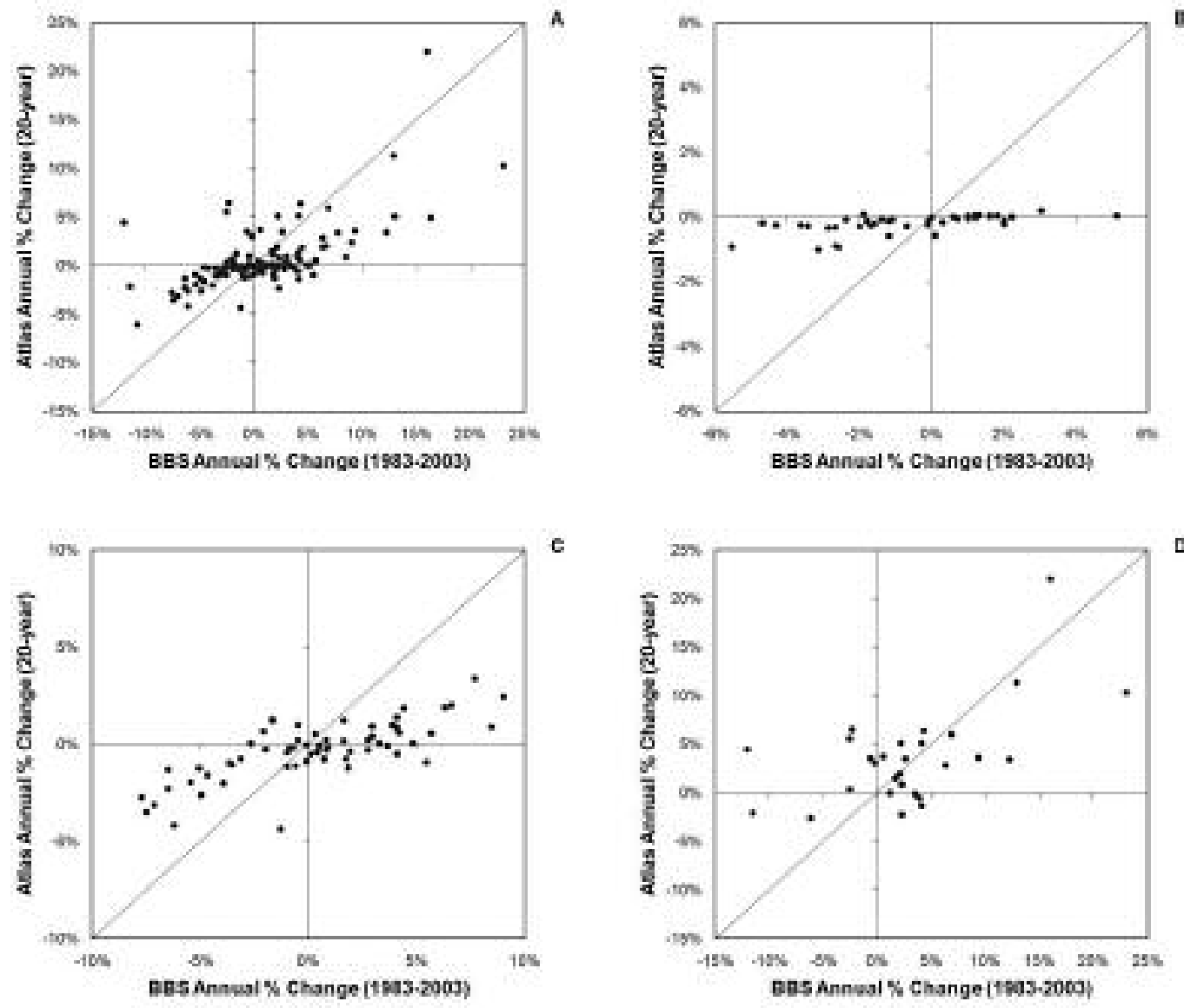

D

c

Fig. 5. Estimated changes in detection probability from the first to the second Ontario Breeding Bird Atlas averaged lower than changes in abundance over the same time period estimated from the Breeding Bird Survey for Bird Conservation Region 13, as shown by deviation in the estimates from the 1:1 line. The ratio was 60\% across all species (A); $13 \%$ for species found in more than $80 \%$ of atlas squares (B); 38\% for species found in 20\% to 80\% of atlas squares (C); and 68\% for species found in less than $20 \%$ of atlas squares (D).

captured by adjusting for quantity of effort. However, comparisons with future atlases, assuming they use point counts as were done for the second atlas, will allow for much more reliable estimates of actual changes in abundance, at least for moderately common and common species. Another major limitation of atlases is that they are typically repeated only at 20-year intervals, which means they cannot detect changes in population status during intervening periods.

\section{Canadian Migration Monitoring Network}

The Canadian Migration Monitoring Network includes a series of bird observatories along the southern edge of Ontario (Fig. 6) that carry out standardized observations, usually combined with banding, throughout the spring and/or autumn migrations each year (Hussell 1997). The longest-running stations are at Long Point Bird Observatory, where standardized counts began in 1961, but several other stations in Ontario have been operating since the 1990s.

Strengths: Counts from migration stations have the potential to provide information on trends of breeding populations from large areas of northern Canada, which are difficult to access in the breeding season (Francis and Hussell 1998). Therefore, they provide information on several species that are not adequately monitored by any other annual survey. CMMN stations also provide many other types of information on migration ecology, including information on energetics, stopover behaviour, migration routes and timing of migration. These can be useful for management of birds during migration and can be used to evaluate some of the ecological consequences of environmental factors such as climate change.

Limitations: Although isotope analyses provide some information on the breeding origins of migrants (Dunn et al. 2006b), population trends still cannot be tied to specific breeding areas, and hence cannot be used to evaluate the impacts of management activities, such as forestry practices, except crudely at very broad scales (e.g., provincial or national). There are also statistical challenges associated with data analysis, especially because methods are not currently available to combine data from different stations to calculate regional or national status or trends of any species. High yearto-year variation in numbers of birds stopping at a station decreases the precision of trend estimates. Results may be biased due to changes in proportions of birds being detected (e.g., due to observer effects or habitat change) or changes in the proportions of migrants stopping at the station (e.g., due to habitat change or changes in migratory routes). 


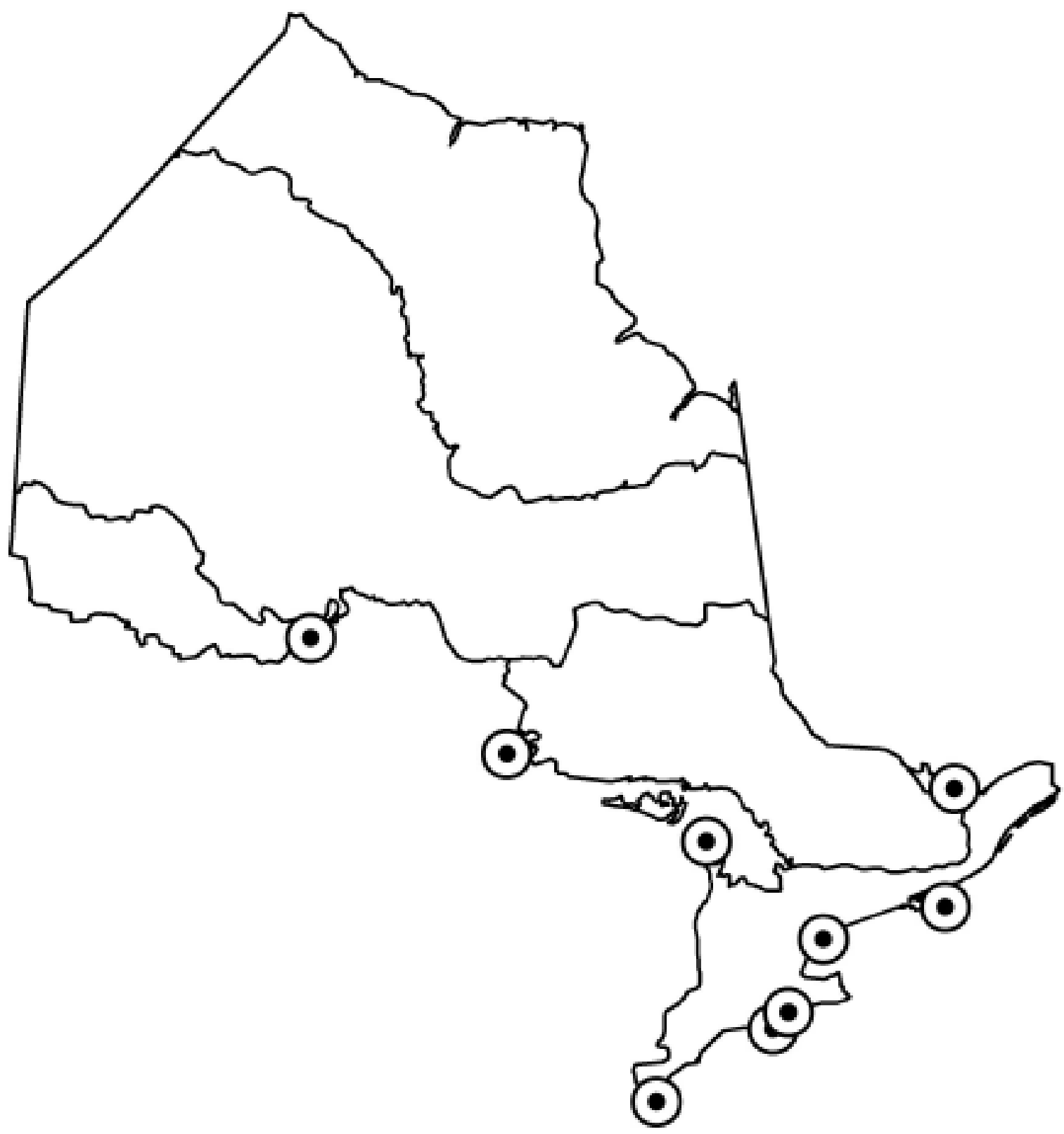

Fig. 6. Several stations in the Canadian Migration Monitoring Network probably sample mainly birds that breed in central and northern Ontario, but the proportion of birds from different BCRs or different parts of a BCR is uncertain and likely varies among species and among years.

\section{Ontario Forest Bird Monitoring Program}

The Forest Bird Monitoring Program consists of clusters of 3 to 5 point count stations in selected forest interior locations that are surveyed twice each breeding season (Welsh 1995). Information on habitat at each station is recorded. Most surveys are in BCR 13 and the southern parts of BCR 12, with only a few plots in BCR 8 (Fig. 7).

Strengths: This program provides information on habitat associations of interior forest birds and hence can contribute to development of predictive models for forest management. It also provides information on population trends of birds within forested habitat, which, together with information on population trends from multi-habitat surveys (such as BBS), may help to determine whether any observed population changes are being driven by changes in the amount of breeding habitat or other factors.

Weaknesses: Data from these surveys cannot be used to calculate regional population trends of forest birds, because sites are not randomly selected and only some habitats are sampled. Results cannot be extrapolated to a broader landscape without additional information such as trends in the amount of forested habitat and trends in other types of habitats. The survey also has limited geographical coverage within Ontario (Fig. 7). 


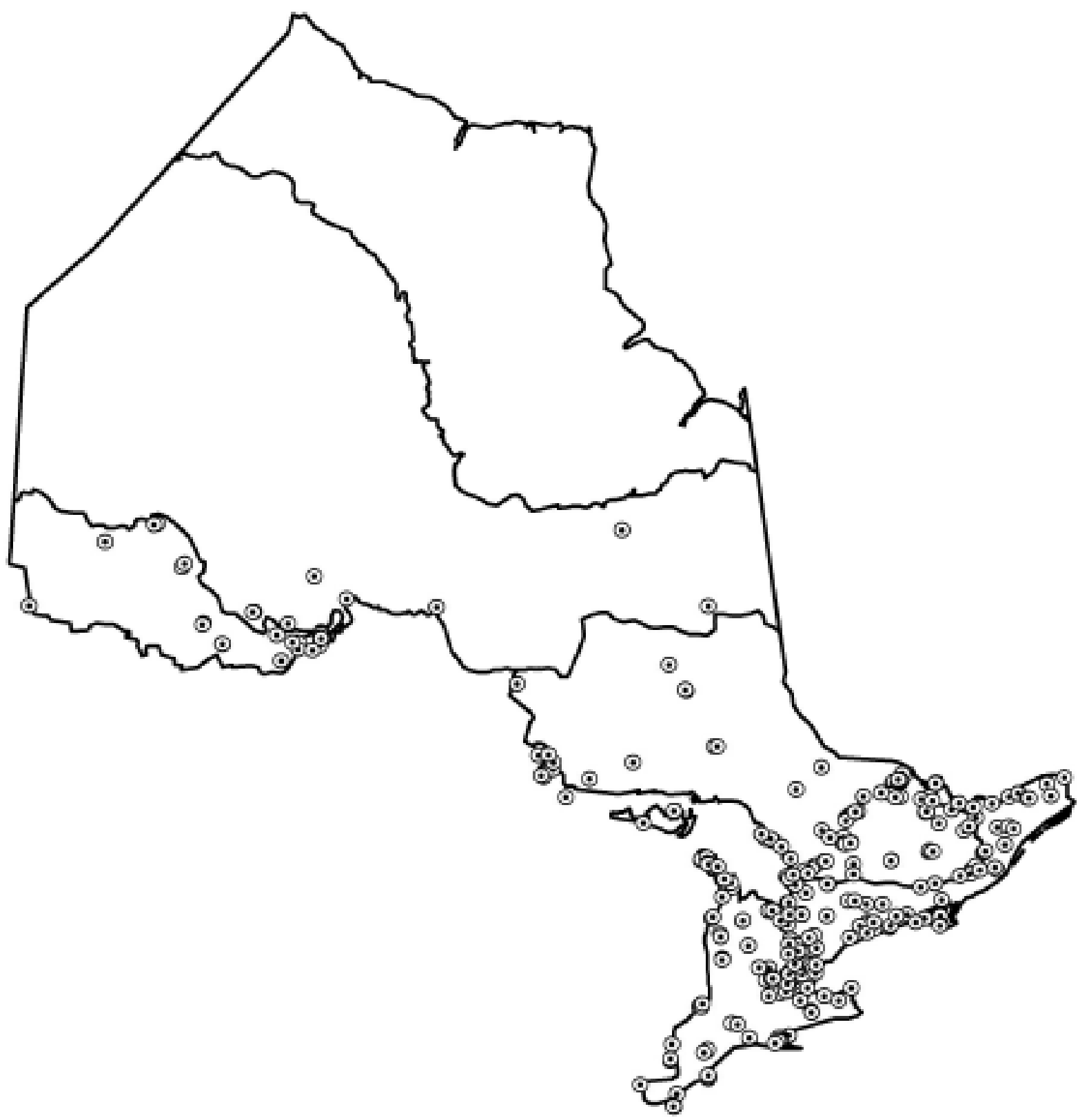

Fig. 7. Distribution of sampling stations for the Forest Bird Monitoring Program in Ontario. Most sampling locations are situated within mature forest, and thus are not representative of the broader landscape.

\section{Ontario Nocturnal Owl Survey}

The Nocturnal Owl Survey is a 10-stop roadside point count survey using a combination of call playback and passive listening for owls (Crewe and Badzinski 2006). Call playback targets Saw-whet Owl (Aegolius acadicus) and Barred Owl (Strix varia) in Central Ontario; Boreal Owl (A. funereus) and Great Gray Owl (Strix nebulosa) in northern Ontario (Fig. 8). The survey began in 1995 and has extensive coverage throughout much of $\mathrm{BCR} 12$ and the roaded areas of BCR 8 .

Strengths: This survey provides sufficient data for 5 species of owls in Ontario (the target species plus Great
Horned Owl (Bubo virginianus)) that are not well monitored by other surveys to help assess their population trends, distribution and status (Crewe and Badzinski 2006). Stop-level survey data could potentially be used to provide some information on the impacts of management activities on owl populations at a medium scale (1- to 2 - $\mathrm{km}$ radius landscapes) if combined with maps of forest management practices.

Weaknesses: Annual variation in breeding behaviour, such as timing and breeding propensity related to small mammal population cycles or weather, can have large effects on detectability of owls and cannot be distinguished from changes in owl populations. Many route locations were not 


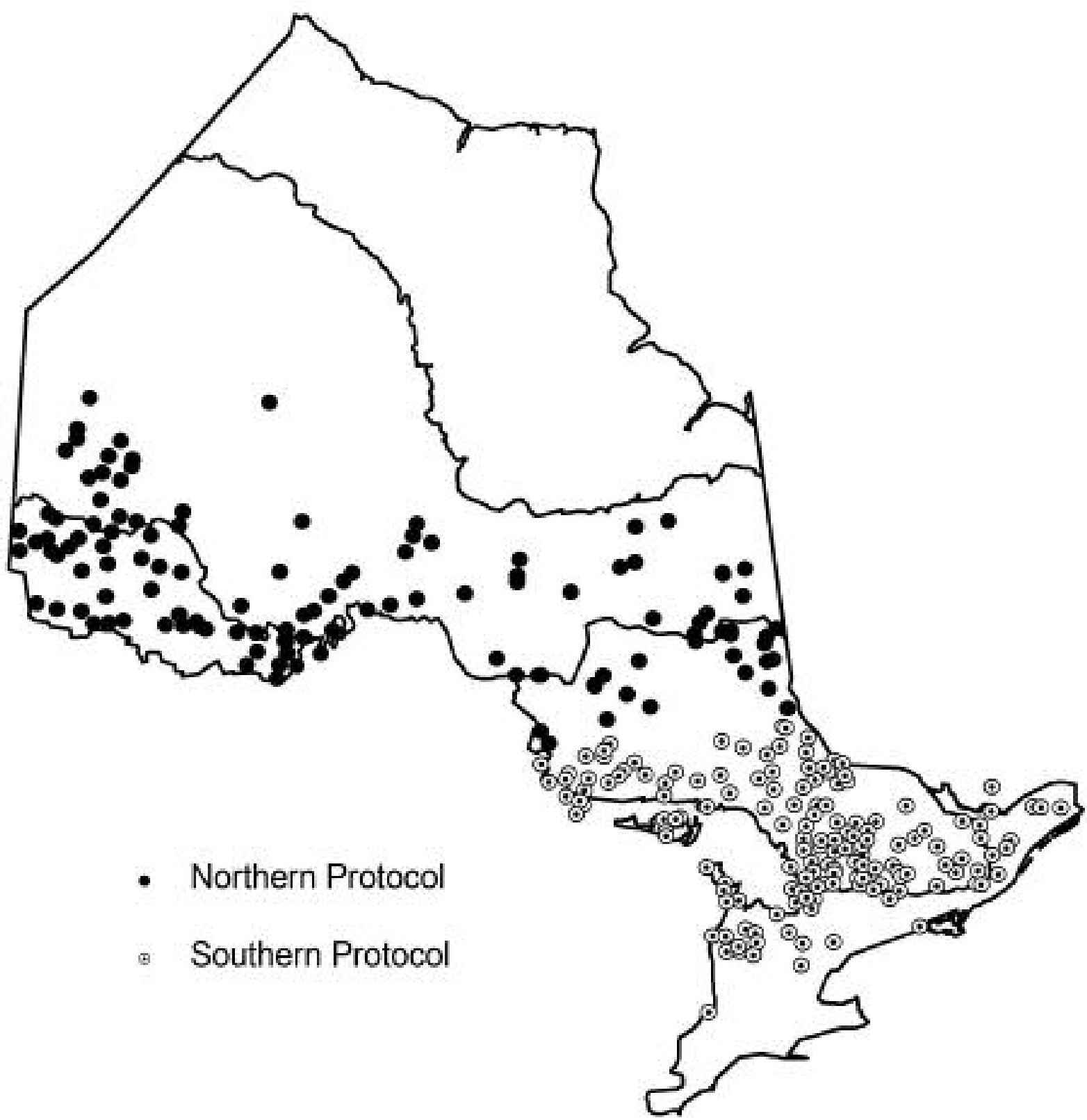

Fig. 8. Distribution of routes on the Ontario Nocturnal Owl survey. Not all routes have been run every year.

selected randomly and, as with other roadside surveys, there may be some bias in the habitats sampled.

\section{Aerial waterfowl surveys}

Black Duck Joint Venture helicopter surveys are carried out on a systematic grid of $5 \times 5 \mathrm{~km}$ plots throughout much of BCR 12 and the eastern portions of BCR 8 (Fig. 9; Lepage and Bordage 2003). All wetlands in the plots are mapped and surveyed at low levels by helicopter to locate all waterfowl and various other bird species readily identified from the air. The helicopter survey is complemented by line transect surveys flown using fixed wing aircraft that overlap the helicopter plot areas but also cover much of northwestern Ontario where they are coordinated with prairie waterfowl surveys.

Strengths: The helicopter survey was statistically designed to provide reliable information on population status of American Black Ducks (Anas rubripes) at an adequate level of precision to support the adaptive harvest management strategy. It also provides similar information on population status and trends of many other waterfowl in the region and some other wetland associated birds. It is one of a limited number of surveys in Ontario explicitly developed to evaluate changes in population in response to management of a species (Foonesbeck and Conroy 2004). 


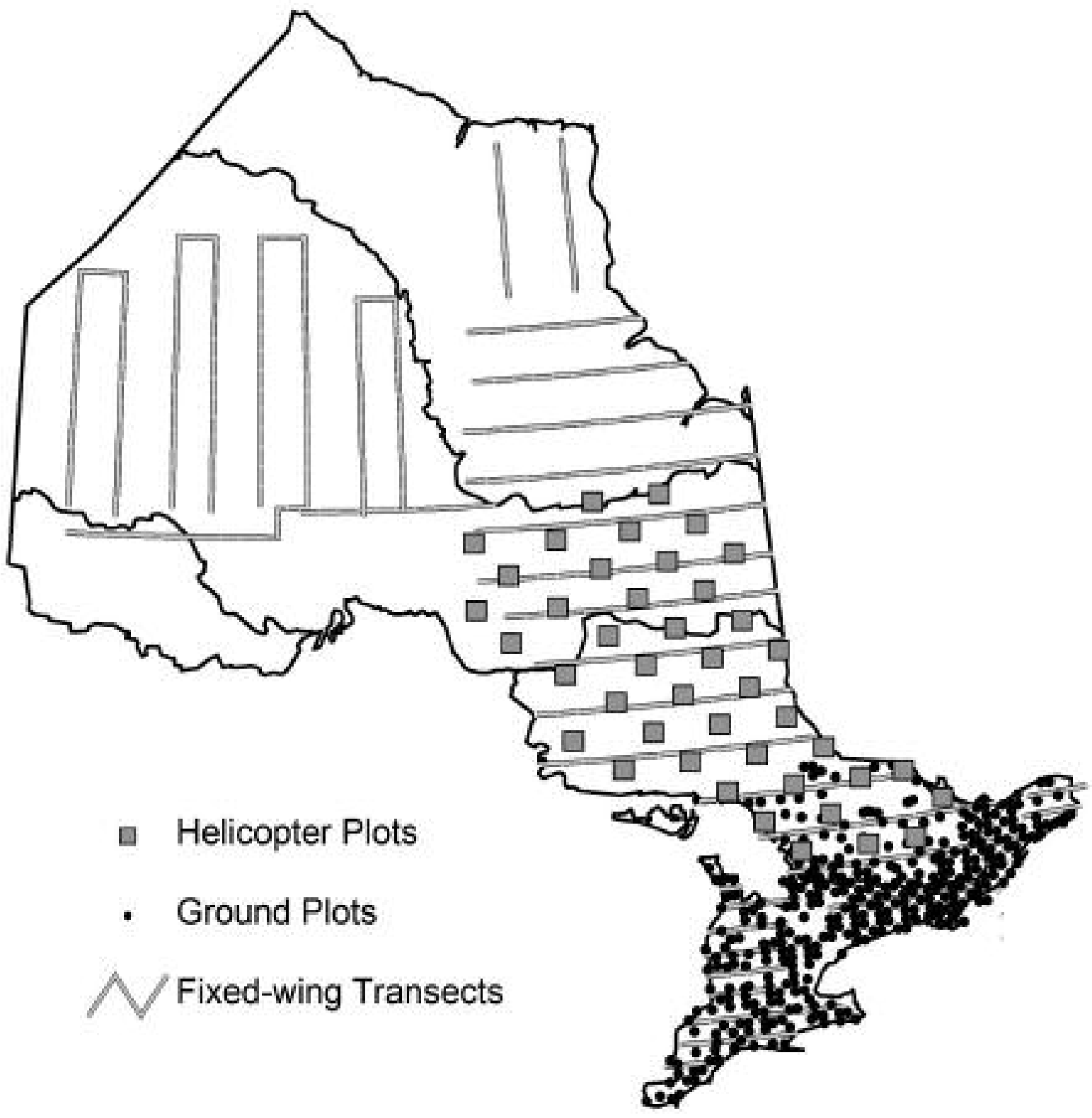

Fig. 9. Distribution of $5 \times 5 \mathrm{~km}$ aerial helicopter plots for the Black Duck Joint Venture, line transect waterfowl surveys from fixed wing aircraft, as well as ground-based survey plots from the Southern Ontario waterfowl survey. The fixed-wing transects obtain reliable data on fewer species of waterfowl than the helicopter surveys.

Weaknesses: These surveys only sample species that can be identified from aircraft. Detectability is not estimated but likely varies considerably among species; changes in observers could also cause some bias, especially for non-target species, though probably less for helicopter than fixedwing airplane surveys. Species that use both open water and habitats away from open water are sampled unevenly. Portions of the survey areas flown with fixed-wing aircraft obtain information on many fewer species of waterfowl. There is also some redundancy in areas surveyed by both helicopters and fixed wing aircraft.

\section{Southern Ontario waterfowl surveys}

The Southern Ontario waterfowl survey counts all waterfowl detected on ground-based $0.8 \times 0.8 \mathrm{~km}$ plots randomly selected in 2 strata, with the constraint that they be close to a road (Dennis et al. 1989). All suitable waterfowl habitat within each plot, as identified from aerial photos and the ground, is surveyed on foot or by canoe, and all species of waterfowl are recorded to estimate the number of pairs. The survey is timed to coincide with the early nesting season of mallards (Anas platyrhyncos) and black ducks (Dennis et al. 1989). Plots are surveyed on a rotating basis every 2 or 3 years. 
Strengths: The survey provides detailed information on population status of many waterfowl species within the survey area, including relatively good estimates of total population sizes, because the survey detects nearly all pairs within each plot. Survey data could potentially be used to estimate detectability from fixed-wing aircraft surveys in the same area.

Weaknesses: Sample methods are not consistent with waterfowl surveys elsewhere in Ontario, and hence it does not easily feed into estimates of population status at larger geographic scales. Survey timing is optimized for the most common breeding waterfowl species and may underestimate early or late nesting species.

\section{Enhancing Bird Monitoring Programs in Ontario}

Enhancing bird population monitoring requires consideration of who will use the information and for what purposes, what type of information and how much is required at different geographical scales to meet these purposes, and then determining the most cost-effective methods to obtain the information.

In Ontario, both federal and provincial governments have some responsibility for bird conservation. At a national level, several pieces of legislation implicate the Federal Government in bird conservation and management activities including the Migratory Bird Convention Act (1994) and the Species at Risk Act (2002). Environment Canada has responsibility for implementation of these Acts for migratory birds, and undertakes many activities related to bird conservation and management, including support of many national-level monitoring programs. A developing driver for monitoring information is related to regulations currently under development that will regulate incidental take of birds as a result of a broad range of activities including, among others, forest management. These regulations will require information on whether management activities are able to sustain healthy populations of birds.

At the provincial level, the Fish and Wildlife Conservation Act (1997) provides some protection for selected non-game bird species in Ontario, while the Endangered Species Act (2007) provides specific protection to species at risk in the province. From the perspective of forest birds, the Crown Forest Sustainability Act (CFSA) (1994) is also relevant, as it requires that Ontario's Crown forests be managed to conserve ecological processes and biological diversity and minimize adverse effects on animal life, including birds, while allowing a sustainable timber harvest. Policy documents such as Ontario's Biodiversity Strategy and "Our Sustainable Future" advance an ecological approach to resource management, conservation of biodiversity, application of the precautionary approach, and the importance of inventory, monitoring, and assessment programs (OMNR 2005a, b). A condition of the Class Environmental Assessment Approval for Forest Management on Crown Lands in Ontario was that the Ontario Ministry of Natural Resources continue to implement a wildlife population monitoring program for terrestrial vertebrates (OMOE 2003; see Condition 30). The purpose of this monitoring program is to assess the sustainability of forest management activities on Crown Lands in Ontario with regard to maintaining wildlife populations as components of healthy forest ecosystems (CFSA 1994, OMOE 2003).

One of the challenges in developing appropriate monitoring is to define quantitative objectives against which progress should be measured. Most policy or legislative drivers such as the CFSA mentioned above, provide only qualitative objectives. Neither CFSA nor the Class Environmental Assessment approval defines the precision or nature of the monitoring program required (beyond that it should occur on Crown Lands with commercial forestry) nor an objective measure of what is meant by a healthy forest ecosystem. The monitoring program must therefore define its own goals, objectives and monitoring questions based upon this broad legislative and policy intent.

The bird conservation plans currently being developed for each of the BCRs in Canada may help with setting conservation objectives. Plans for landbirds in some BCRs have already been developed (e.g., PIF British Columbia and Yukon 2003, Ontario PIF 2006), and are currently being expanded into plans that will cover all bird groups. These plans make use of available information on the status and trends of each species at a national level to identify priority species and population objectives, and then roll these down to regional levels based on various factors, including the estimated proportions of the populations of each species in each jurisdiction. They also identify some of the management actions required to achieve those objectives.

Measuring progress towards these population objectives requires monitoring information that can be integrated across BCRs to estimate the national status of each species, but with sufficient precision in each BCR to estimate the responsibility of that BCR for each species and to measure progress towards population objectives for those species identified as priorities within each BCR.

Any new monitoring programs should be designed to provide information not only on the status of bird species, but also on the effects of proposed management actions (Nichols and Williams 2007). Development activities such as forestry, mining, energy development (including renewable energy such as wind turbines or biofuels), and urban expansion all have the potential to affect bird populations and communities. Some of these, such as forestry activities, are likely to enhance populations of selected bird species, but may adversely affect other species, over time and space. Other activities, such as wetland restoration, may be undertaken specifically to enhance ecological values including those for birds. Activities such as energy development or urban expansion may have some negative local impacts, but may still be acceptable if population level impacts are small or the effects are mitigated by other measures (including offsets such as protection of wintering habitat or reduced greenhouse gas emissions). However, there is always uncertainty in predictions of the impacts of particular management actions. To reduce this uncertainty, quantitative predictions should be developed based on one or more competing models, and monitoring designed to provide feedback on bird population responses, thus reducing the uncertainty (Nichols and Williams 2007).

Another consideration in evaluating monitoring programs is deciding how much monitoring is actually required for effective decision-making. This has rarely been objectively analyzed for any ecological monitoring program. Bart et al. (2004) suggested that bird population monitoring programs should be able to detect a $50 \%$ decline over a 20 -year period with alpha of 0.10 and power of 0.80 at a large regional level. However, Field et al. (2007) suggested that alpha and power 
should be adjusted to consider the relative costs and consequences of detecting or failing to detect change. Nichols and Williams (2007) argued against using any arbitrary alpha cutoff, and instead advocated a decision-making paradigm in which data from monitoring programs are used to evaluate the weight of evidence in support of particular hypotheses or management options. Considerably more development work is required to determine the optimum investment in monitoring for effective decision-making.

For evaluation of status of birds in Ontario, Blancher et al. (2009) found that current monitoring programs in Ontario are sufficient to provide fairly reliable information on population trends for most bird species in BCRs 12 and 13, but not for most species in the more northern BCRs 7 and 8 , due largely to very limited coverage in these northern BCRs by most of the major existing multi-species surveys (Fig. 2). The only survey with substantial coverage in BCR 7 is the Breeding Bird Atlas but, as noted above, there are concerns about the reliability of trend estimates from the first to second atlas. Migration monitoring also provided some information that was considered relevant to assessing some species in BCRs 7 and 8 , though owing to uncertainty in the origins of birds being counted, it was used as a primary source for only $26 \%$ of species in BCR 8 (Blancher et al. 2009) and 3\% of species in BCR 7.

Several approaches could be considered for obtaining better bird status information in the northern BCRs. If the Breeding Bird Atlas can be repeated using similar coverage and methods to the second atlas, comparison of point count data will provide much more reliable trend information. However, the atlas is only scheduled to be repeated after another 20 years, which may be insufficient for management purposes. Although migration monitoring may provide some trend information in between atlas repeats, it is not specific to BCRs, as noted above. Some components of the atlas such as point counts in northern Ontario could be repeated at shorter intervals (e.g., every 5 years) if necessary. In Australia, the second Australian bird atlas (Barrett et al. 2003) evolved into an ongoing continuous monitoring program, using a Web site called "Birdata" that can be used to assemble data using the same sampling methods as for the atlas. ${ }^{7}$ However, the Australian atlas was largely a passive approach, dependent on volunteers. This may not be sufficient to provide adequate coverage in northern Ontario, where there are significant logistical challenges to accessing many areas and substantial resources may be required.

An alternative approach for enhancing status information in the north might be to develop a new monitoring program. This could be focussed on filling fill gaps in areas that are currently under-sampled, or alternatively, if well designed and effective, it could be designed to replace some existing programs. A multi-species monitoring and inventory program (e.g., Manley et al. 2006) could achieve economies of scale by integrating bird monitoring programs into a sampling regime that also samples other taxa. The Alberta Biodiversity Monitoring Program was developed to sample many different plant and animal groups including birds (Stadt et al. 2006). Sampling stations are situated throughout the province in a systematic grid, and visited on a rotating pattern such that each

$\overline{7}$ http://www.birdsaustralia.com.au/our-projects/atlas-birdata.html location is resurveyed every 5 years. Incorporation of recent technological developments such as automated systems for recording and analyzing bird songs has the potential to increase the effectiveness and feasibility of sampling birds as part of a multi-species program (e.g., Hobson et al. 2002, Agranat 2007).

Ideally, such a program would also incorporate assessment of the impacts of specific management activities. However, monitoring programs to assess specific management actions are often required at different scales from those required for assessing BCR or range-wide objectives (Dunn et al. 2006a). One approach to dealing with this disparity of scale is a combination of small-scale monitoring efforts associated with specific management activities, and broader-scale monitoring, such as those described above, to provide information at the BCR or other large scale. The broad-scale programs could serve both as context and controls for evaluating local information. Different organizations may be involved in implementing programs at each scale, but use of standardized monitoring protocols (e.g., Dunn et al. 2006a, EC-CWS 2007) can facilitate integration of data from multiple projects, thus enhancing power to understand the overall impact.

\section{Conclusions}

Although there are already many bird monitoring programs in Ontario, there are several ways that these could be improved to fill gaps in coverage and to provide better information to support decisions related to management activities. We suggest that the most effective way to enhance bird monitoring programs in Ontario will be to bring together the various agencies and organizations with similar needs for monitoring data to design, develop, and implement a path forward. Such an initiative should involve federal agencies (Environment Canada, Parks Canada), provincial agencies (Ontario Ministry of Natural Resources), environmental non-government organizations with an interest in bird monitoring, and industries that carry out activities that have potential impacts on migratory bird populations or habitats. Many of these groups have already worked together to implement the second Ontario Breeding Bird Atlas. The most challenging step will be to define precisely and quantitatively the type, geographic distribution and amount of monitoring data required to make effective management decisions for each of the players, whether it be priority-setting, evaluating progress towards population objectives, or evaluating the effectiveness of specific management activities such as forestry practices. Such an analysis would lay the foundation for identifying the most appropriate surveys designs, sample sizes, etc. and comparing them with what has already been developed. If done well, this would also demonstrate the economic benefits, in terms of improved decision-making, of carrying out the monitoring programs, and hence could be used to help secure the required resources to implement enhanced bird monitoring programs in Ontario.

\section{Acknowledgements}

Many of the ideas on developing, designing and evaluating monitoring programs presented in this paper have benefited from discussions with the team leading an evaluation of Canadian bird monitoring programs for Environment Canada, as well as the team that prepared the U.S. NABCI report on monitoring (U.S. NABCI Committee 2007). How- 
ever, the ideas presented are those of the authors and do not represent an official position of their respective agencies. Ken Abraham, Debbie Badzinski, Mike Cadman, Tara Crewe, Constance Downes, Don Fillman, Jack Hughes, David Hussell, Denis Lepage, Jon McCracken, Don McNicol, Bruce Pond, Ken Ross, Rich Russell, Lisa Venier and Russ Weeber all contributed to the evaluation of existing Ontario monitoring programs, as part of an evaluation of the current status of birds in Ontario (Blancher et al. 2009). Ian Thompson and 2 anonymous reviewers provided helpful comments to improve the organization of the manuscript.

\section{References}

Agranat, I.D. 2007. Automatic Detection of Cerulean Warblers Using Autonomous Recording Units and Song Scope Bioacoustics Software. Wildlife Acoustics, unpublished report. Available at http://www.wildlifeacoustics.com/songscope/cerulean/.

Baillie, S.R. 1990. Integrated population monitoring of breeding birds in Britain and Ireland. Ibis 132: 151-166.

Barrett, G., A. Silcocks, S. Barry, R. Cunningham and R. Poulter. 2003. The New Atlas of Australian Birds. CSIRO Publishing, Collingwood, Australia.

Bart, J., K.P. Burnham, E.H. Dunn, C.M. Francis and C.J. Ralph. 2004. Goals and strategies for estimating trends in landbird abundance. Journal of Wildlife Management 68: 611-626.

Blancher, P., M.D. Cadman, B.A. Pond, A.R. Couturier, E.H. Dunn, C.M. Francis and R.S. Rempel. 2007. Changes in Bird Distributions between Atlases. In M.D. Cadman, D.A. Sutherland, G.G. Beck, D. Lepage and A.R. Couturier (eds.). Atlas of the Breeding Birds of Ontario, 2001-2005. pp. 32-48. Bird Studies Canada, Environment Canada, Ontario Field Ornithologists, Ontario Ministry of Natural Resources, and Ontario Nature, Toronto, ON.

Blancher, P.J., R.D. Phoenix, D.S. Badzinski, M.D. Cadman, T.L. Crewe, C.M. Downes, D. Fillman, C.M. Francis, J. Hughes, D.J.T. Hussell, D. Lepage, J.D. McCracken, D.K. McNicol, B.A. Pond, R.K. Ross, R. Russell, L.A. Venier and R.C. Weeber. 2009. Population trend status of Ontario's forest birds. The Forestry Chronicle 85(2): 184-201.

Cadman, M.D., P.F.J. Eagles and F.M. Helleiner (eds.). 1987. Atlas of the Breeding Birds of Ontario. University of Waterloo Press, Waterloo, ON. xx + 617 p.

Cadman, M.D., D.A. Sutherland, G.G. Beck, D. Lepage and A.R. Couturier (eds.). 2007. Atlas of the Breeding Birds of Ontario, 2001-2005. Bird Studies Canada, Environment Canada, Ontario Field Ornithologists, Ontario Ministry of Natural Resources, and Ontario Nature, Toronto, ON. xxii + 706 p.

Crewe, T. and D. Badzinski. 2006. Ontario Nocturnal Owl Survey: 2005 Final Report. Unpublished report. Bird Studies Canada. Available at http://www.bsc-eoc.org/ontowlrpt2000.html.

Crown Forest Sustainability Act (CFSA). 1994. S.O. 1994, Chapter 25. Available at http://www.e-laws.gov.on.ca/html/statutes/english/ elaws_statutes_94c25_e.htm.

Dennis, D.G., G.B. McCullough, N.R. North and B. Collins. 1989. Surveys of breeding waterfowl in southern Ontario, 1971-87. Canadian Wildlife Service Progress Note 180. 4 p.

Dunn, E.H., J. Bart, B.T. Collins, B. Craig, B. Dale, C.M. Downes, C.M. Francis, S. Woodley and P. Zorn. 2006a. Monitoring bird populations in small geographic areas. CWS Special Publication.

Dunn, E.H., C.M. Francis, P.J. Blancher, S.R. Drennan, M.A. Howe, D. Lepage, C.S. Robbins, K.V. Rosenberg, J.R. Sauer and K.G. Smith. 2005. Enhancing the scientific value of the Christmas Bird Count. Auk 122: 338-346.

Dunn, E.H., K.A. Hobson, L.I. Wassenaar, D.J.T. Hussell and M.L. Allen. 2006b. Identification of summer origins of songbirds migrating through southern Canada in autumn. Avian Conservation and Ecology - Écologie et conservation des oiseaux 1(2): 4. [online] http://www.ace-eco.org/vol1/iss2/art4/.
Dunn, E.H., J. Larivée and A. Cyr. 1996. Can checklist programs be used to monitor populations of birds recorded during the migration season? Wilson Bulletin 108: 540-549.

[EC-CWS] Environment Canada - Canadian Wildlife Service. 2007. Recommended protocols for monitoring impacts of wind turbines on birds [online]. Available at http://www.cws-scf.ec.gc.ca/ publications/eval/index_e.cfm.

Endangered Species Act. 2007. Statutes of Ontario 2007, Chapter 6. Available at http://www.e-laws.gov.on.ca/html/statutes/english/ elaws_statutes_07e06_e.htm.

Field, S.A., P.J. O'Connor, A.J. Tyre, H.P. Possingham. 2007. Making Monitoring Meaningful. Austral Ecology 32: 485-491.

Field S.A., A.J. Tyre, J.M. Rhodes, N. Jonzen and H.P. Possingham. 2004. Minimizing the cost of environmental management decisions by optimizing statistical thresholds. Ecology Letters 7: 669-75.

Fish and Wildlife Conservation Act. 1997. Statutes of Ontario 1997, Chapter 41. Available at http://www.e-laws.gov.on.ca/html/ statutes/english/elaws_statutes_97f41_e.htm.

Foonesbeck, C.J. and M.J. Conroy. 2004. Application of integrated Bayesian modeling and Markov chain Monte Carlo methods to the conservation of a harvested species. Animal Biodiversity and Conservation 27: 267-281.

Francis, C.M. and D.J.T. Hussell. 1998. Changes in numbers of land birds counted in migration at Long Point Bird Observatory, 1961-1997. Bird Populations 4: 37-66.

Hobson, K., R.S. Rempel, H. Greenwood, B. Turnbull, and S.L. Van Wilgenburg. 2002. Acoustic surveys of birds using electronic recordings: new potential from an omnidirectional microphone system. Wildlife Society Bulletin 30: 709-720.

Hussell, D.J.T. 1997. Monitoring migrants to detect changes in populations of birds breeding in Canada: present status and future prospects. In E.H. Dunn, M.D. Cadman and J.B. Falls (eds.). Monitoring bird populations: the Canadian experience. pp. 43-48. Canadian Wildlife Service Occasional Papers 95.

IUCN. 2001. IUCN Red List Categories and Criteria: Version 3.1. IUCN Species Survival Commission. IUCN, Gland, Switzerland and Cambridge, UK. ii +30 p.

Lambert, J.D., T.P. Hodgman, E.J. Laurent, G.L. Brewer, M.J. Iliff and R. Dettmers. 2009. The Northeast Bird Monitoring Handbook. American Bird Conservancy. The Plains, Virginia. 32 p.

Lepage, C. and D. Bordage. 2003. Black Duck Joint Venture (BDJV) [online]. Environment Canada, Canadian Wildlife Service, Québec Region. Available at http://www.qc.ec.gc.ca/faune/sauvagine/html/ bdjv.html.

Link, W.A. and J.R. Sauer. 2002. A hierarchical analysis of population change with application to the Cerulean Warbler. Ecology 83: 2832-2840.

Link, W.A., J.R. Sauer and D.K. Niven. 2006. A hierarchical model for regional analysis of population change using Christmas Bird Count data, with application to the American Black Duck. Condor 108:13-24. Manley, P.N., B. Van Horne, J.K. Roth, W.J. Zielinski, M.M. McKenzie, T.J. Weller, F.W. Weckerly and C. Vojta. 2006. Multiple species inventory and monitoring technical guide. Gen. Tech. Rep. WO-73. Washington, DC: U.S. Department of Agriculture, Forest Service, Washington Office. 204 p.

Migratory Birds Convention Act. 1994. Statutes of Canada 1994, chapter 22. Available at http://laws.justice.gc.ca/en/M-7.01/.

Nichols, J.D. and B.K. Williams. 2007. Monitoring for Conservation. Trends in Ecology and Evolution 21: 668-673.

O'Connor, R.J., E. Dunn, D.H. Johnson, S.L. Jones, D. Petit, K. Pollock, C.R. Smith and E. Welling. 2000. A programmatic review of the North American Breeding Bird Survey: Report of a peer review panel to the U.S. Geological Survey Patuxent Wildlife Research Center, Laurel, MD., February 2000. Available at http:// www.pwrc.usgs.gov/bbs/bbsreview/.

[OMNR] Ontario Ministry of Natural Resources. 2005a. Protecting What Sustains Us: Ontario's Biodiversity Strategy, 2005. Ministry of Natural Resources, Peterborough, Ontario. $44 \mathrm{p}$. 
2005b. Our Sustainable Future: Ministry of Natural Resources Strategic Directions. Ministry of Natural Resources, Toronto, ON 22 p.

[OMOE] Ontario Ministry of the Environment. 2003. Order under the Environmental Assessment Act. MNR-71. Declaration Order regarding MNR's Class Environmental Assessment Approval for Forest Management on Crown Lands in Ontario. Ministry of the Environment. Toronto, ON.

Ontario Partners in Flight (PIF). 2006. Ontario Landbird Conservation Plan: Boreal Hardwood Transition, North American Bird Conservation Region 12. Version 1.0. Ontario Ministry of Natural Resources, Bird Studies Canada, Environment Canada. Unpublished.

Partners in Flight (PIF) British Columbia and Yukon. 2003. Canada’s Great Basin Landbird Conservation Plan. Version 1.0. Partners in Flight British Columbia and Yukon, Delta, BC. 100 p. Available at http://www.pifbcyukon.org/3c.html.

Rich, T.D., C.J. Beardmore, H. Berlanga, P.J. Blancher, M.S.W. Bradstreet, G.S. Butcher, D.W. Demarest, E.H. Dunn, W.C. Hunter, E.E. Inigo-Elias, J.A. Kennedy, A.M. Martell, A.O. Panjabi, D.N. Pashley, K.V. Rosenberg, C.M. Rustay, J.S. Wendt and T.C. Will. 2004. Partners in Flight North American Landbird Conservation Plan. Cornell Lab of Ornithology, Ithaca, NY. 88 p. Available at http://www.partnersinflight.org/cont_plan/default.htm.

Robbins, C.S., D. Bystrak and P.H. Geissler. 1986. The Breeding Bird Survey: Its first fifteen years, 1965-1979. U. S. Fish and Wildlife Service Resource Publication 157. 196 p.

Sauer, J.R., J.E. Fallon and R. Johnson. 2003. Use of North American Breeding Bird Survey data to estimate population change for bird conservation regions. Journal of Wildlife Management 67: 372-389.
Species at Risk Act. 2002. Statutes of Canada 2002, chapter 29. Available at http://laws.justice.gc.ca/en/S-15.3/index.html.

Stadt, J.J., J. Schieck and H.A. Stelfox. 2006. Alberta Biodiversity Monitoring Program - monitoring effectiveness of sustainable forest management planning. Environmental Monitoring and Assessment 121: 33-46.

Thomas, L. and K. Martin. 1996. The importance of analysis method for Breeding Bird Survey population trend estimates. Conservation Biology 10:479-490.

Thogmartin, W.E., J.R. Sauer and M.G. Knutson. 2004. A hierarchical spatial model of avian abundance with application to cerulean warblers. Ecological Applications 14: 1766-1779.

U.S. Geological Survey. 2007. Strategic Plan for the North American Breeding Bird Survey: 2006-2010: U.S. Geological Survey Circular 1307. 19 p. Available at http://pubs.usgs.gov/circ/2007/1307/.

U.S. NABCI Committee. 2000. North American Bird Conservation Initiative Bird Conservation Region Descriptions. A Supplement to the North American Bird Conservation Initiative Bird Conservation Regions Map. U.S. Fish and Wildlife Service, Arlington, VA. 38 p. Available at http://www.nabci-us.org/aboutnabci/bcrdescrip.pdf.

U.S. NABCI Committee. 2007. Opportunities for Improving Avian Monitoring. U.S. North American Bird Conservation Initiative Report. Division of Migratory Bird Management, U.S. Fish and Wildlife Service, Arlington, VA. 50 p. Available at http://www.nabcius.org/aboutnabci/monitoringreportfinal0307.pdf.

Welsh, D.A. 1995. An Overview of the Ontario Forest Bird Monitoring Program in Canada. In C. Ralph, C.J., J.R. Sauer and S. Droege (tech. eds.). Monitoring bird populations by point counts. Gen. Tech. Rep. PSW-GTR-149. p. 93-98. U.S. Department of Agriculture, Forest Service, Pacific Southwest Research Station, Albany, CA. 